\title{
MARITIME LASER SCANNING AS THE SOURCE FOR SPATIAL DATA
}

\author{
Paweł Burdziakowski', Ph. D. \\ Artur Janowski ${ }^{1}$, Ph. D. \\ Arthem Kholodkov², Ms. C. \\ Krzysztof Matysik², Bs. C. \\ Maciej Matysik², Bs C. \\ Marek Przyborski ${ }^{1}$, Assoc. Prof. \\ Jakub Szulwic ${ }^{1}$, Ph. D. \\ Paweł Tysiąc ${ }^{1,2}$, Bs. C. \\ Aleksander Wojtowicz ${ }^{1,2}$, Bs. C. \\ 1) Gdansk University of Technology, Gdańsk, Poland \\ 2) „APEKS” Ltd., Gdańsk, Poland
}

\begin{abstract}
The rapid development of scanning technology, especially mobile scanning, gives the possibility to collect spatial data coming from maritime measurement platforms and autonomous manned or unmanned vehicles. Presented solution is derived from the mobile scanning. However we should keep in mind that the specificity of laser scanning at sea and processing collected data should be in the form acceptable in Geographical Information Systems, especially typical for the maritime needs. At the same time we should be aware that data coming from maritime mobile scanning constitutes a new approach to the describing of maritime environment and brings a new perspective that is completely different than air and terrestrial scanning.

Therefore, the authors, would like to present results of an experiment aimed at testing the possibilities of using mobile scanning at sea. Experiment was conducted in the harbour and the associated environment of neighbouring southern coast of the Baltic Sea.
\end{abstract}

Keywords: mobile laser scanning; maritime laser scanning; GIS for harbours; measurements of the sea coast; boat-based scanning

\section{INTRODUCTION}

Laser scanning (LiDAR - Light Detection and Ranging) is an effective tool to support the supply with geodetic data (geospatial) of GIS (Geographic Information Systems) in many applications. It is used for efficient, rapid and largely comprehensive high-quality data acquisition of the expected accuracy. In solutions related to the sea, the mobile laser scanning conducted from vessels gains in importance (Maritime Laser Scanning - MarLS). It belongs to a group of Mobile Laser Scanning (MLS), but the specificity of a ship movement and conditions of marine environment introduces a differences that should be taken into account in the planning and conducting of scanning from the sea.

In the context of the usefulness of data, it can be argued that MarLS can be a great addition to the electronic nautical charts used among of the of marine navigators and pilots (Electronic Nautical Charts - vessels; FMS - Navigation Display aircrafts). These are systems in which the characteristics of availability and reliability must be above $99.5 \%$ (SoL systems - EGNOS Safety of Life). In the appropriately processed form, data from laser scanning, mobile (MLS), air (Airborne Laser Scanning - ALS) or maritime (MarLS) could be the basis for a supply with data of the highly augmented reality (Augmented Reality - AR) which makes it simpler for the people responsible for the control of their vessels to move under the conditions of degraded visibility, at night or under any other situations when the standard mark relating to the position of their vessels (floating/air) on an electronic chart might be insufficient.

In addition, in the light of contemporary existing threats (e.g. terrorism, maritime disasters), the issues of critical infrastructures objects safety have become a very important. Changes taking place in the world also affect the situation in developed countries so far considered as safe, and it unfortunately means that every object of critical coastal infrastructure or a maritime transport means could be a potential target of a terrorist attack. Hence, the issues related to the wide security, including the so-called perimeter security become very important. The use of technical means to protect objects is now becoming a common procedure. Ensuring the protection of huge companies - such as refineries, airports and harbours - requires the use of highly advanced solutions. In this matter, the technologies from the field of optoelectronic systems, IT systems, spatial information management systems (GIS) are applied. The GIS can be considered as a platform 
for the integration of different sources of information within single system ensuring the visualization of danger sources as well as the broad planning and simulation of all kinds of activities related to ensuring a high level of security of the protected objects. The basis for the effectiveness of such a system is reliable information about the space. An example of the method of obtaining such information may be a project of scanning the seacoast along with the harbour infrastructure which is focused on the system approach to the safety of such objects. Wide opportunities currently offered by spatial information management systems make it possible to construct GIS platform which provides the basis for the development of the multimodal system - a tool and support for people responsible for the efficiency of anti-crisis activity in case of such circumstances.

Within the frames of the experiment, the test imaging of Władysławowo harbour with a part of sea coast (including cliffs) on the southern coast of the Baltic Sea was performed. In order to assess the suitability of MarLS data, the analyses related solely to this technology were presented without replenishing the data with ALS and geodetic measurements carried out on the land.

\section{EXPERIMENT REALIZATION METHOD}

To acquire spatial data, a scanning set based on Riegl GmbH VMZ-400 mobile scanning system was used. The system consisted of VZ-400 scanner (primarily developed for the purpose of stationary scanning) and multiple frequency and multi-system GNSS Global Navigation Satellite System) receiver connected with IMU (Inertial Measurement Unit), which is responsible for the accurate determination of the parameters of platform movement. Laser scanner (e.g VMZ-400) is a device quite often tested in a mobile solutions $[1,2,4,8,12,15,17]$, as well as for the purpose of scanning from surface of the water $[9,15,22,25]$, but scanning the open sea is still an innovative and problematic solution. VZ-400/VMZ400 scanner is capable of operating in any inclination which makes it useful under difficult or untypical conditions such as sea conditions. Depending on the selected scanning mode Long Range (LR) and High Speed (HS) - the scanning range is up to $600 \mathrm{~m}$ (registration up to 42 thousands points per second) or $350 \mathrm{~m}$ (up to 122 thousands points per second) for optimal atmospheric conditions and physical properties of the scanned surfaces.

Supporting platform for the scanning was system $\mathrm{K} / \mathrm{H}$ Tucana ship (hydrographic boat). This ship has overall length of $21.87 \mathrm{~m}$, width of $5.70 \mathrm{~m}$, draught of $1.75 \mathrm{~m}$ and the maximum displacement of 80 GT (Gross Tonnage). A large longitudinal and lateral stability of $\mathrm{K} / \mathrm{H}$ Tucana was essential for the correct scanning especially in terms of scan density. As an experiment, the portion of the Baltic coast at the section from the fishing harbour in Władysławowo to the cliffs in the western part of Jastrzębia Góra was subjected to imaging. Thus allowed to obtain the imaging in form of the scanned port infrastructure (Fig. 1), plane sandy beaches (Fig. 2) and the steep sea coasts (Fig. 3).
The workstation of the scanning system is located on the left side of the upper deck. The platform was fixed rigidly to the available, fixed points of the deck (Fig. 3). The method of installation and the characteristic construction of the upper deck forced a constant slope around the transverse and longitudinal axis of the vessel $[3,19,20,23,24]$. The values of pitch (rotation around the side-to-side axis), roll (rotation around the front-to-back axis) also were changing during the scan because of the rolling of the ship, which - summed up with a constant slope - is presented in figures 4 and 5 .

After initializing the parameters of IMU/GNSS system and scan, the registration of data obtained from scanning on mobile PC (with increased resistance to weather conditions) were started. This computer was one part of the user segment, responsible for the control of the hybrid scanner operation. Despite the good geometry of the GNSS space segment, the yaw angle measurement errors occurred (around the $\mathrm{Z}$ axis perpendicular to the plane of vessel deck) due to its instability. This stability can be achieved only through the so-called dynamic alignment. In mobile scanning, it consists in alternating acceleration and deceleration and sudden changes in movement direction of the scanning unit before and during the registration in MLS technology. While it is easily achievable in terms of road traffic, whereas in case of moving of the scanning system in the water (MarLS) this method can not be used satisfactorily.

Scanning was started within the port area, so the difficulty was to develop a high speed of the ship and to perform calibration manoeuvres before scanning. Despite the large number of available GNSS satellites, yaw angle measurement errors occurred (rotation around the vertical axis). Low speed of the unit became an advantage in terms of the density of the recorded points. To obtain unit movement data, the system of LV POS and RiAcquire program, supplied by Riegl $\mathrm{GmbH}$, were used. In mobile scanning with the use of VZ-400 scanner, the information about the vehicle movement is used - its activity is recognized thanks to DMI device (Distance Measurement Indicator). When scanning from the sea, it is not possible, which makes it impossible to detect the motion what is in turns important in case of slow port manoeuvring with unstable IMU parameters. Thus, the maritime laser scanning may be characterized by an additional impact of this parameter's uncertainty errors. However, the development of IMU/GNSS positioning technology may have a significant effect on the elimination of this phenomenon [11].

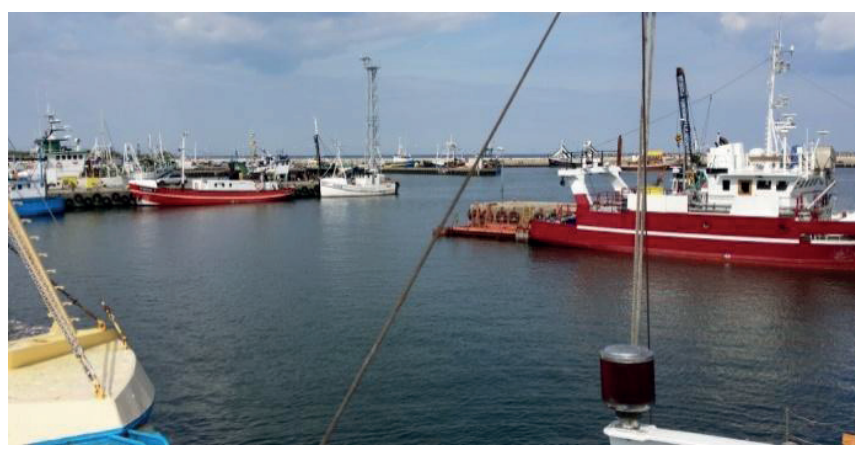

Fig. 1. The area of the fishing port-manoeuvring among the wharves and other vessels. 


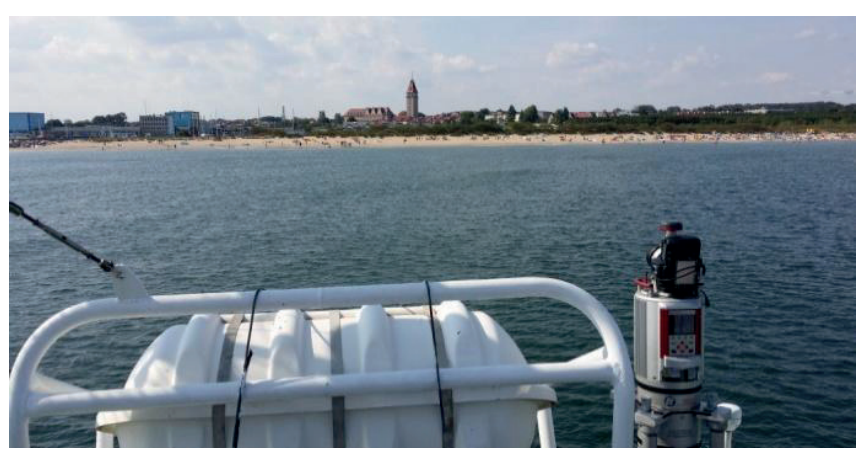

Fig. 2. Scanning the sea beaches of a small slope of the terrain

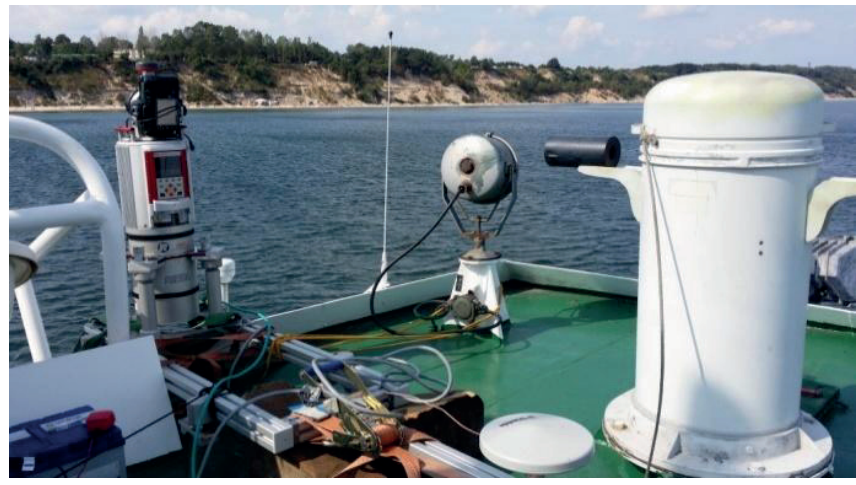

Fig. 3. Scanning cliffs and steep sea coasts

When planning maritime works using MarLS, it is necessary to take into account the hydrometeorological conditions. For MarLS, it is particularly important to take into account the transparency of air?, air temperature, wind and sea conditions. During the preparation to the experiment data from http://model.ocean.univ.gda.pl/ and http://www. meteo.pl/ has been used [13].

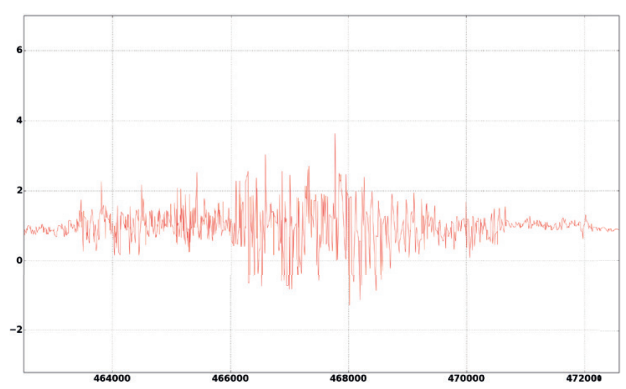

Fig. 4. Change of the roll value during measurements ( $X$-axis - time expressed in seconds, $Y$-axis - the slope expressed in degrees)

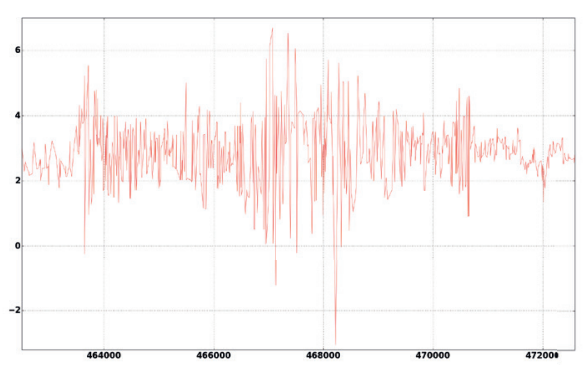

Fig. 5. Change of the pitch parameter value during measurements (X-axis - time expressed in seconds, Y-axis - the slope expressed in degrees)

\section{SCANNING RESULTS}

Data study is the standard procedure consisting of the scanner movement trajectory alignment (Fig. 6) and appending next scan records to it. As a result of the alignment only with GNSS reference stations network (ASG-EUPOS: formal geodetic control network in Poland) the expected positioning accuracy is a sub-meter value. In case of using reference points and planes measured with geodetic instruments and GNSS receivers based on the geodetic control network and after attaching them to the measurement, the results of measurements with error of 0.1-0.2 $\mathrm{m}$ for trajectory positioning are achievable. In comparison to the land-based measurements [11] - especially in urban areas and covered by high vegetation - the open horizon is a facilitation in case of performing measurement from the sea, so we are able to obtain very good factors for GNSS measurements and a large number of satellites used for positioning.

\begin{tabular}{|c|c|c|c|}
\hline $\begin{array}{l}\text { Processing Mode: } \\
\text { Adjustment executed in: } \\
\text { Trajectory adjusted on: }\end{array}$ & $\begin{array}{r}\text { Mobile Laser } \mathrm{Sc} \\
00 \\
\end{array}$ & & \\
\hline \multicolumn{4}{|c|}{$\begin{array}{l}\text { Trajectoy: sbet_Mission 1_ok (1) } \\
\text { Statistics of Position Corrections }\end{array}$} \\
\hline $\begin{array}{l}\text { Along-Track: } \\
\text { Cross-Track: } \\
\text { Height: } \\
\text { Total Positional Deviation: }\end{array}$ & $\begin{array}{r}\text { abs mean } \quad[\mathrm{m}] \\
0.0268 \\
0.0207 \\
0.0109 \\
0.0424 \\
\end{array}$ & $\begin{array}{r}\text { rms } \quad[\mathrm{m}] \\
0.0534 \\
0.0534 \\
0.0174 \\
0.0775 \\
\end{array}$ & $\begin{array}{r}\max \quad[\mathrm{m}] \\
0.4024 \\
0.4749 \\
0.0876 \\
0.4864 \\
\end{array}$ \\
\hline \multicolumn{4}{|c|}{ Statistics of Orientation Corrections } \\
\hline $\begin{array}{l}\text { Roll Angle: } \\
\text { Pitch Angle: } \\
\text { Yaw Angle: } \\
\text { Total Angular Deviation: }\end{array}$ & $\begin{array}{r}0.00334 \\
0.00439 \\
0.14855 \\
0.14910 \\
\end{array}$ & $\begin{array}{r}0.01604 \\
0.01187 \\
0.35749 \\
0.35804 \\
\end{array}$ & $\begin{array}{r}0.16692 \\
0.07907 \\
2.79574 \\
2.80090 \\
\end{array}$ \\
\hline
\end{tabular}

Fig. 6. Alignment and calculation of scanner motion trajectory.

In the data coming from the alignment of scanning system, there are interesting corrections of the positions (Fig. 7) and orientation (Fig. 8). Large position corrections are highly visible - up to $0.49 \mathrm{~m}$ - for the position at the beginning and at the end of the scan, when vessel was located in harbour. At the correction of orientation, it was possible to observe bigger angular corrections - up to 2.80 degree - within the port (but only for the yaw parameter).

This is the consequence of the need to reach by the ship correct speed and shape of the trajectory necessary for initializing the gyro. The device, after initialization, is working properly, providing appropriate adjustments in positioning and orientation at a speed greater than the required minimum. At low speed of the ship gyroscope stops providing satisfactory adjustments for a certain precision measurements (you can see it on the ends of the charts Fig. 7 and 8; in ranges: from the beginning to 462990 seconds and from 472100 seconds to the end - in the harbour and from 462990 to 472100 seconds - open sea).

The development of trajectory has allowed to locate it in the harbour in. $\mathrm{kml}$ format which is possible to be imported to GIS for the common mapping systems (Fig. 9). 


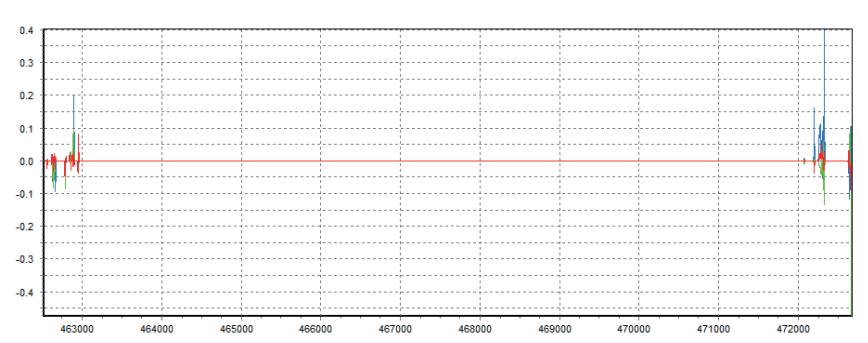

Fig. 7. Correction of scanning system position (X-axis - time expressed in seconds, Y-axis - adjustments to the position in meters - blue colour, cross track-green colour and height - red colour)

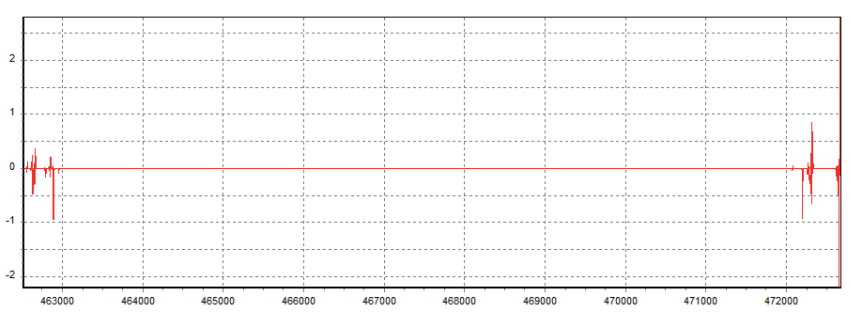

Fig. 8. Correction of scanning system orientation (X-axis - time expressed in seconds, Y-axis - adjustments to the slope expressed in degrees, roll - blue colour, pitch - green colour and yaw - red colour)

The development of trajectory has allowed to locate it in the harbour in $\mathrm{kml}$ format which is possible to be imported to GIS for the common mapping systems (Fig. 9).

Using the analysis related to the points cloud characteristics it became possible to make an assessment of the scan accuracy for the harbour area (Fig. 9) and to determine the density of the points cloud for the scanned coast (Fig. 13). The "deviation" accuracy parameter has the particular importance for the quality of scan (Fig. 10) - the higher the value, the higher the measurement uncertainty for the given point on the scan. It is possible to notice the regularity, according to which this parameter is increased in areas where the laser beam falls at a slight angle ("slips"), refracts and reflects taking into account the changes in the density of the centre (e.g. in a shallow water). Whereas in the figure 13 it is possible to observe the variable density of the scan at seashore which is specific for MarLS. Variable-density areas are arranged in lanes perpendicular to the motion of the vessel. This imperfection results from the poor compensation of ship speed, resulting from the wave.

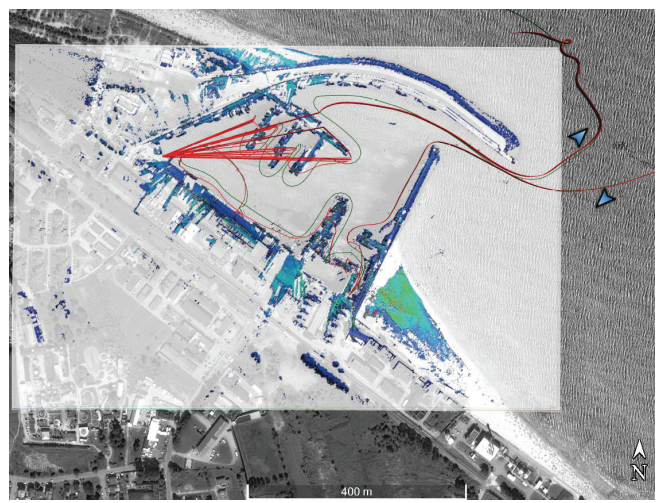

Fig. 9. Trajectory of the scanner movement imposed on Google Earth ${ }^{\mathrm{m}}$ for the port: raw red colour and aligned - green, with the designation of exit and entrance to the port

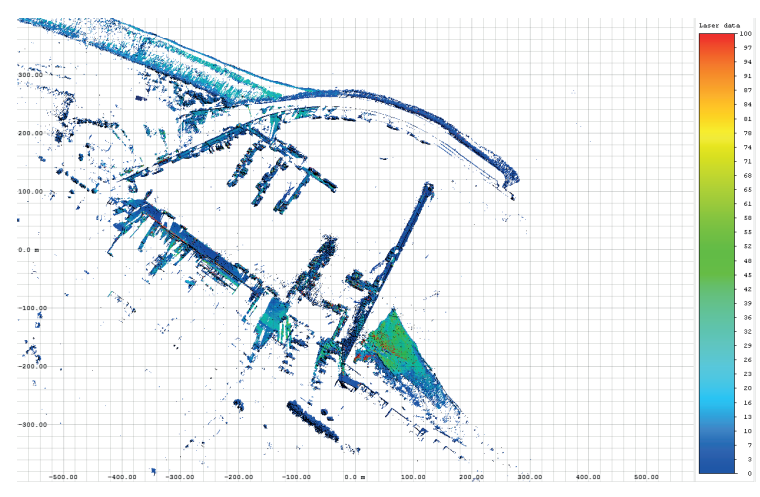

Fig. 10. MarLS data visualization for Władysławowo port with the determination of the accuracy parameter - deviation (Laser data - the level of losing the confidence to the quality and accuracy of the data)

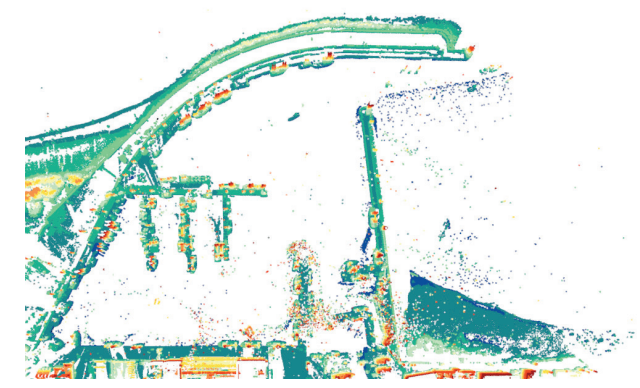

Fig. 11. MarLS data visualization for Władysławowo harbour taking into account the parameter of height above sea level

The use of geodetic spatial references system enabled to provide the characteristics of the height above sea level for the registered data (Fig. 11). As a result of carrying out the experiment, it was possible to obtain the spatial data (with reference to the geodetic spatial reference system), from which it is possible to carry out spatial analyses related to the seashore and port infrastructure (Fig. 12).

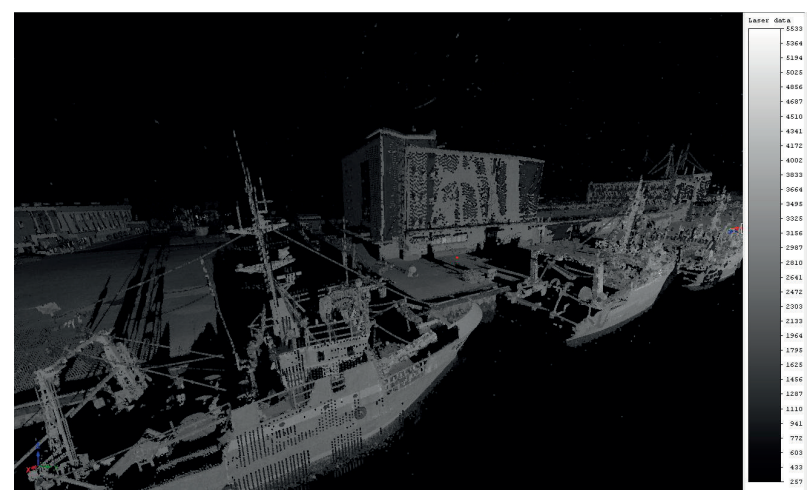

Fig. 12. MarLS visualization for vessels in harbour and port infrastructure (Laser data - number of points per square meter)

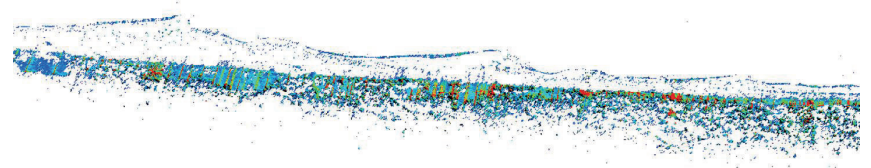

Fig.13. MarLS visualization for the coast fragment with the cloud density parameter of approximately 30 points per $m 2$ for the green colour to approximately 100 points per $m 2$ for the red colour 


\section{DISCUSSION AND CONCLUSIONS}

The results of the performed experiment show that MarLS might be very useful to supplement the maps of approaches to harbours and coasts with satisfactory accuracy (about $0.10 \mathrm{~m}$ ). The results and the obtained models can be a source for supplying marine charts systems (also within the frames of sailing directions) with the information based on visualizations and 3D presentations. Experiments carried out in recent years by various authors suggest that the use of a 3D maps improves the quality of navigation $[5,6,18,21,22]$, and may also help to improve the safety of vessels and to protect water regions against danger $[7,10,16,17]$. Ease of obtaining spatial data and technological capabilities of scanning allow to assess the presented solution as the technology that in the short time will become the standard method of obtaining information about the coast of seawaters and inland waters. The combination of data from maritime scanning and terrestrial scanning with photogrammetry (especially for the items requiring high-precision of imaging - e.g. aid in navigations) and with the ALS air scanning (especially for horizontal surfaces and slopes with the small inclination angle) will allow for the construction of a satisfactory 3D model for the supply of geographic information systems and for the complementation of nautical maps and electronic navigation systems on vessels. It seems to be forward-looking to implement LiDAR data $[1,12]$ along with realized analyses and algorithms into MarLS as well as sea to implement sea cliffs geometry studies based on TLS $[7,10]$.

Specific problems are related to the difficulty to compensate the variable slope of the scanning unit and variable ship speed associated with the waviness. The characteristics of this factor refer mainly to wave parameters: its period, length and height. The parameter should be purposefully skipped, because the measurement make sense on a certain sea state, specified with some margin. When taking into account only the height of waves, the range from 0.5 to 1.25 should be the maximum range, which corresponds to the sea state of 3 .

Keeping in mind the quality of the measurement, its density, uniform distribution of points (so similar criteria as for air scanning), it is necessary to refer to these parameters which make it difficult the calm and uniform vessel movement on the water (the lower and longer wave the rolling of the hull, transferred onto the rigidly installed platform of the scanner is smaller). The occurrence of a short hull tugging wave should be connected with the fact, that within the scope of development there will be lanes. At the point of temporary slowdown of the translational motion, the density is higher and when the motion of the wave accelerates the vessel, the density of points is much smaller.

\section{REFERENCE}

1. Blaszczak-Bak W., Janowski A., Kaminski W., Rapinski J.: Application of the Msplit method for filtering airborne laser scanning data-sets to estimate digital terrain models. International Journal of Remote Sensing, 36(9), (2015) 2421-2437, DOI:10.1080/01431161.2015.1041617
2. Borrmanna D., Nüchtera A., Đakulović M., Maurović I., Petrović I., Osmanković D., Velagić J.: A mobile robot based system for fully automated thermal 3D mapping. Advanced Engineering Informatics, 28(4) (2014) 425-440, DOI:10.1016/j.aei.2014.06.002

3. Byoung-Guk Min, Hee-ja Jeong, Tae-Jin Ha, Joon-Seub Cha, Nam-Ho Kim: Implementation of navigation system available for marine leisure ship. International Journal of Control and Automation, 7(3) (2014) 29-36, DOI: 10.14257/ijca.2014.7.3.04

4. Chen C., Liu H., Liu Y., Zhuo X.: High accuracy calibration for vehicle-based laser scanning and urban panoramic imaging and surveying system. MIPPR 2013: Multispectral Image Acquisition, Processing, and Analysis, SPIE 8917 (2013) 89170Y, DOI: 10.1117/12.2031466

5. Chybicki A., Kulawiak M., Lubniewski Z., Dabrowski J., Luba M., Moszynski M., Stepnowski A.: GIS for remote sensing, analysis and visualisation of marine pollution and other marine ecosystem components. Proceedings of the 2008 1st International Conference on Information Technology, ISBN: 978-1-4244-2244-9 (2008) 223-226

6. Dong-Taur S., Lo D.C., Cheng-Wu C., Yi-Chang H.: The integration of nautical charts to reconstruct 3D harbor area models and apply assisted navigation. Natural Hazards, 66(2) (2013) 1135-1151, DOI: 10.1007/s11069-012-0516-7

7. Dudzinska-Nowak J., Wezyk P.: Volumetric changes of a soft cliff coast 2008-2012 based on DTM from airborne laser scanning (Wolin Island, southern Baltic Sea). Journal of Coastal Research, 70 (2014) 59-64

8. Elseberg J., Borrmann D., Nüchter A.: Algorithmic solutions for computing precise maximum likelihood 3D point clouds from mobile laser scanning platforms. Remote Sensing, 5(11) (2013) 5871-5906, DOI: 10.3390/rs5115871

9. Hohenthal J., Alho P., Hyyppä J., Hyyppä H.: Laser scanning applications in fluvial studies. Progress in Physical Geography. 35(6) (2011) 782-809, DOI: $10.1177 / 0309133311414605$

10. Janowski A., Jurkowska A., Lewczuk D., Szulwic J., Zaradny A.: Assessment of cliff stability after the demolition of the engineering facilities. 14th SGEM GeoConference on Science and Technologies in Geology, Exploration and Mining. ISBN 978-619-7105-08-7 ISSN 1314-2704, 2 (2014) 115-124, DOI: 10.5593/SGEM2014/B12/S2.016

11. Janowski A., Nowak A., Przyborski M., Szulwic J.: Mobile indicators in GIS and GPS positioning accuracy in cities. Rough Sets and Intelligent Systems Paradigms, RSEISP 2014 Book Series: Lecture Notes in Computer Science (LNCS) 8537 (2014) 309-318, DOI: 10.1007/978-3-31908729-0_31 
12. Janowski A., Rapinski J.: M-split estimation in laser scanning data modeling. Journal of the Indian Society of Remote Sensing, 41(1) (2013) 15-19, , DOI: 10.1007/ s12524-012-0213-8

13. Jedrasik J., Szymelfenig M.: Ecohydrodynamic model of the Baltic Sea. Part 2. Validation of the model, Oceanologia, 47(4) (2005) 543-566

14. Jia-Liang S., Duo-Hu H., Quan H., Tie-Ying L., Chao Z.: Research of analysis and three dimensional display on international standard chart. Geomatics \& Spatial Information Technology, ISSN 1672-5867 (2014)

15. Kholodkov A., Matysik K., Matysik M., Szulwic J., Tysiąc P., Wojtowicz A.: Morski skaning laserowy infrastruktury portowej na przykładzie portu we Władysławowie (in Polish). Logistyka. 6 (2014) 14317-14328

16. Kulawiak M., Chybicki A., Moszynski M.: Web-based GIS as a tool for supporting marine research. Marine Geodesy, 33(2-3) (2010) 135-153, Art. No. PII 923578807, DOI: $10.1080 / 01490419.2010 .492280$

17. Michoud C., Carrea D., Costa S., Derron M.H., Jaboyedoff M., Delacourt C., Maquaire O., Letortu P., Davidson R.: Landslide detection and monitoring capability of boatbased mobile laser scanning along Dieppe coastal cliffs, Normandy. Landslides, 12(2) (2014) 403-418, DOI: 10.1007/s10346-014-0542-5

18. Przyborski M.: Possible determinism and the real world data. Physica A - Statistical Mechanics and its Applications, 309(3-4) (2002) 297-303, Art. No. PII S03784371(02)00565-4, DOI: 10.1016/S0378-4371(02)00565-4

19. Schopp P., Klingbeil L., Peters C., Manoli Y.: Design, geometry evaluation, and calibration of a gyroscopefree inertial measurement unit. Sensors and Actuators A-Physical, 162(2) (2009) 379-387

20. Sørensen A.J.: Dynamic positioning control systems for ships and underwater vehicles. Encyclopedia of Systems and Control (2014) 1-10, DOI: 10.1007/978-1-4471-51029_122-1

21. Stateczny A., Bodus-Olkowska I.: Hierarchical hydrographic data fusion for precise port electronic navigational chart production. Telematics - Support for Transport TST, 471 (2014) 359-368, DOI: 10.1007/978-3-662-45317-9_38

22. Studnicka N., Zach G.: Mobile laser scanning in Venice: Grand Canal in scan and image data. GIM international, 25(4) (2011) 20-23

23. Townsend N.C., Shenoi R.A.: Control strategies for marine gyrostabilizers. IEEE Journal of Oceanic Engineering, 39(2) (2013) 243-255, DOI: 10.1109/JOE.2013.2254591
24. Witkowska A., Tomera M., Smierzchalski R.: A backstepping approach to ship course control. International Journal of Applied Mathematics and Computer Science 17(1) (2007) 73-85, DOI: 10.2478/v10006-007-0007-2

25. Wojtowicz A., Tysiac P., Szulwic J., Janowski A.: Airborne and mobile laser scanning in measurements of sea cliffs on the southern Baltic. 15th International Multidisciplinary Scientific GeoConference SGEM 2015, June 18-24, 2015, 1(2) (2015) 17-24, DOI: 10.5593/SGEM2015/B12/S2.003

\section{CONTACT WITH AUTHOR}

\author{
Jakub Szulwic \\ Paweł Burdziakowski \\ Artur Janowski \\ Marek Przyborski \\ Paweł Tysiąc \\ Aleksander Wojtowicz \\ Faculty of Civil and Environmental Engineering \\ Gdansk University of Technology \\ Narutowicza 11/12 \\ 80-233 Gdansk \\ Poland
}

\author{
Arthem Kholodkov \\ Krzysztof Matysik \\ Maciej Matysik \\ Paweł Tysiąc \\ Aleksander Wojtowicz
}

Engineering Services Company „APEKS” Ltd.

Jaskowa Dolina 81 80-286 Gdańsk

Poland 